\title{
CORRESPONDÊNCIA DE ALMEIDA GARRETT: espe- lho de uma personalidade e de uma época
}

\section{Almeida Garrett}

\section{Correspondência para Rodrigo da Fonseca Magalhães.}

\section{Lisboa: Imprensa Nacional-Casa da Moeda (IN-CM), 2016 (329 p.)}

1.

Tradicionalmente, mau grado o género epistolar ser classificado como um "menor" na hierarquia dos vários géneros, os Estudos Literários, em geral, e a História da Literatura, em particular, sempre concederam grande importância à correspondência dos escritores, na sua diversa tipologia e variedade de formas, seja pela sua riqueza estilística, seja pela sua ampla função informativa. Enquanto privilegiado miroir de l'âme e discurso em diálogo com as obras literárias, as cartas de escritores atraíram multissecularmente o especial interesse de pesquisadores e de leitores (cf. HAROCHE-BOUZINAC, 1995; e GRASSI, 1998).

Para a presente apreciação crítica, impõem-se duas notas prévias sobre a identificação da obra em causa e o seu enquadramento editorial, bem como sobre o seu editor responsável. Este volume da Correspondência para Rodrigo da Fonseca Magalhães, de Almeida Garrett integra-se no plano, em curso, da Edição das Obras de Almeida Garrett, coordenado pela Professora Ofélia Paiva Monteiro, da Faculdade de Letras da Universidade de Coimbra. Com edição de Sérgio Nazar David (UERJ), segue- 
-se a um outro volume organizado pelo mesmo prestigiado investigador garrettiano, Correspondência Familiar (GARRETT, 2012) ${ }^{1}$.

Deste modo, o presente trabalho insere-se num projecto editorial bem identificado. A coordenador da "Edição Crítica da Obra Completa de Almeida Garrett" esclarece que um dos objectivos visados consiste no "estabelecimento para cada obra [de Garrett], de um texto-base que representa a última forma conhecida da responsabilidade do autor". Para isso, explica que "Serão dados a lume não só os textos publicados em vida do autor - poesia, teatro, ficção narrativa, romanceiro, ensaio, produção jornalística, intervenção oratória -, mas também os que tiveram divulgação editorial póstuma e os que permanecem em versão manuscrita; e proceder-se-á a uma fixação textual acompanhada por um aparato crítico-genético" (p. 9).

Ao mesmo tempo, para avaliarmos o contributo da obra em análise, convém traçar muito brevemente o perfil do responsável pela sua edição. Sérgio Nazar David é Doutor em Teoria da Literatura (UFRJ, 2001), com Pós-Doutorado (Coimbra, 2006) sob a supervisão de Ofélia Paiva Monteiro. Poeta, professor de Literatura Portuguesa (UERJ). Integrou a direcção da Associação Brasileira de Professores de Literatura Portuguesa, ABRALIP (2007-2013). Entre outras instituições científicas, é Membro do Centro de Literatura Portuguesa (CLP) da Universidade de Coimbra (Equipe Garrett); e ainda coordenador da área de Estudos de Literatura (Mestrado e Doutorado, UERJ, 2017-2018); consultor científico do CNPq, da CAPES, da FAPERJ e da Associação Internacional de Lusitanistas (AIL).

Entre variadíssimas publicações sobre a Literatura Portuguesa de Oitocentos e sobre Almeida Garrett em particular, da autoria de Sérgio Nazar David, além de inúmeros artigos em revistas literárias de referência, destaquem-se as seguintes obras: O Século de Silvestre da Silva, vol. I - Estudos sobre Garrett, A. P. Lopes de Mendonça, Camilo Castelo Branco e Júlio Dinis (DAVID, 2007) e O Século de Silvestre da Silva, vol. II - Estudos Queirosianos (DAVID, 2007). É também organizador da

\footnotetext{
${ }^{1}$ Menção Honrosa no Prémio Grémio Literário Português, nesse mesmo ano. Cf. informação sobre outras publicações da Edição Crítica das obras de Almeida Garrett na página institucional do Centro de Literatura Portuguesa (CLP) da Universidade de Coimbra:
}

https://www.uc.pt/fluc/clp/pub/liv/\#edAlmGarrett 
edição crítica de Cartas de Amor à Viscondessa da Luz (DAVID, 2004). Estas e outras informações são a garantia de um crédito científico do perfil do investigador que edita mais este volume da edição crítica das obras garrettianas $^{2}$.

\section{2 .}

Essencial para a reconstituição de uma época, bem como para o íntimo conhecimento da personalidade do homem político e do escritor de génio, a extensa correspondência garrettiana, começou bem cedo a publicar-se, como devidamente salientado por Sérgio Nazar David. ${ }^{3}$

Do ponto de vista da estrutura do volume em questão, Correspondência para Rodrigo da Fonseca Magalhães, de Almeida Garrett, ele compõe-se de uma longa e informadíssima "Introdução geral" (p. 15- 67)"; a que se segue a edição das "cartas para Rodrigo da Fonseca Magalhães" (p. 71-321), culminando num pertinente índice onomástico (p. 323-325).

Para uma fundamentada edição crítica deste epistolário, Sérgio Nazar David teve de elaborar pesquisas fundamentais em bibliotecas e arquivos diversos, com realce para a Biblioteca Geral da Universidade de Coimbra, a Biblioteca Nacional de Portugal (Lisboa), a Direcção-Geral de Arquivos da Torre do Tombo e a Sala Ferreira Lima (universidade de Coimbra). O mesmo é dizer que é absolutamente necessário proceder a um trabalho sério de investigação para fundamentar um trabalho de edição crítica desta natureza.

Este volume é constituído por quase uma centena de cartas, mas precisamente 97, de dimensão desigual, sendo esta correspondência proveniente de várias origens, quer do Espólio de Rodrigo da Fonseca Ma-

2 Sérgio Nazar David também prefaciou a edição brasileira dos Estudos Garrettianos de Ofélia Paiva MONTEIRO (2010, pp. 7-14); e coorganizou volumes como Literatura, História e Política em Portugal (1820-1856), com trabalho de fixação do texto (DAVID, 2007). Para além de prefaciar criticamente obras garrettianas, como a edição das Viagens na Minha Terra (GARRETT, 2013). ${ }^{3}$ Esse pioneirismo pertence ao dedicadíssimo amigo e biógrafo, Francisco Gomes de AMORIM (1881-84), autor de Garrett: Memorias Biographicas, fonte de informação ampla e pertinentemente usada pelo editor desta correspondência garrettiana.

${ }^{4} \mathrm{O}$ leitor interessado dispõe de uma pequena amostra das páginas introdutórias disponível online: https://www.uc.pt/fluc/clp/pub/pub_exc/ECAG_CR 
galhães, quer de outros espólios (cf. p. 23), sendo a maior parte delas cartas particulares (74) e uma pequena percentagem de cartas oficiais (23), estando a maior parte destas cartas sem datação. O mais relevante é estarmos perante 93 cartas inéditas.

Sendo também conhecidas as cartas do interlocutor garrettiano, Sérgio Nazar David opta fundamentadamente por transcrever excertos dessas cartas "sempre que o conteúdo interessava para o esclarecimento de algum passo das cartas de Garrett" (p. 24). Para o editor, as cartas compõem três blocos, que cobrem outros tantos acontecimentos da vida político-cultural portuguesa dos anos a que dizem respeito.

Do ponto de vista da sua amplitude cronológica, esta correspondência inicia-se no período de 1834-36, quando Garrett desempenha a função de Encarregado de Negócios; e termina em 1852, no momento em que acontece o rompimento das relações entre os dois amigos, depois de uma longa e intensa relação de amizade. De permeio, como salienta o editor desta correspondência, ocorrem "os ministérios setembristas e o conturbado período cabralista" (p. 18). Nesse sentido, a leitura destas cartas permite reconstituir e iluminar os meandros de uma época; ao mesmo tempo, representam um contributo para o mais aprofundado conhecimento da riquíssima personalidade de Almeida Garrett (cf. MARTINS, 2018, p. 228).

Destaca-se nestas cartas o perfil de um homem político com ideias bem vincadas, cidadão cosmopolita, independente e criticamente interventivo. Com efeito, além do valor linguístico-estilístico desta correspondência, o conjunto destas cartas permite-nos mergulhar no dia a dia da vida político-cultural deste período intenso da vida portuguesa - nomeadamente a subida ao pode de Costa Cabral e tudo o que se lhe seguiu -, cenário perspectivado através do olhar privilegiado de um homem público, de um escritor e de um estilista da língua, como era Almeida Garrett. Não encontramos nestas cartas considerações especiais sobre a dimensão mais inventiva da obra literária garrettiana, por estarmos perante uma correspondência predominantemente política, como esclarecido pelo editor:

A correspondência para Rodrigo da Fonseca Magalhães é essencialmente política no sentido amplo do termo. Por isso pode lançar luz sobre o papel dos intelectuais portugueses na primeira metade do século XIX; também esclarecerá uma esfera dos estudos garrettianos ainda por explorar, a obra política, nomeadamente Portugal na Balança da Europa, os artigos na imprensa - por vezes em jornais de difícil acesso - e os discursos parlamentares - alguns com versão mais contunden- 
te, no Diário da Câmara dos Deputados, outra posterior, depurada de excessos pelo próprio autor. (p. 21).

Nesta edição das cartas de Garrett para Rodrigo da Fonseca Magalhães, estamos assim perante o diálogo entre dois grandes políticos liberais. Rodrigo da Fonseca Magalhães (1787-1858) notabilizou-se como uma das mais proeminentes figuras do liberalismo em Portugal, tendo desempenhado várias funções ao nível governativo - integrou o Batalhão Académico contra as tropas invasoras francesas (1807), foi deputado, par do reino e várias vezes ministro e chefe do Governo ${ }^{5}$. As suas destacadas qualidades de homem político mereceram-lhe a alcunha de "raposa".

\section{3.}

Como se deixe sugerido, a temática dominante nesta correspondência garrettiana é da maior importância para iluminação histórico-cultural de uma época decisiva da vida portuguesa, com as suas ligações à política internacional. Em face do afirmado, o editor reforça que nestas cartas Almeida Garrett aborda

temas da sua trajetória de homem público como a fundação do Conservatório Geral de Arte Dramática, com a aprovação de 'Estatutos' e 'Regimentos', e a constituição da sua biblioteca; a atuação como Cronista-Mor do Reino; as negociações com os Estados Unidos (Tratado de Comércio e Navegação) e com a França (Convenção Literária e Tratado de Comércio); a construção do Teatro Nacional; as discórdias entre as fações liberais e a guerra civil da Patuleia; a repulsa do miguelismo e do cabralismo; a aproximação às fações mais moderadas do cartismo e do setembrismo (p. 19).

Esta dominante fortemente política não deixa, porém, de permitir articular os temas e as preocupações desta correspondência com a mundividência que atravessa as obras literárias garrettianas da mesma época, como apontado pelo próprio Sérgio Nazar: “É, em síntese, neste contexto que podemos ler algumas cartas de Garrett a Rodrigo da Fonseca Magalhães da década de 40 em consonância com as principais obras literárias

\footnotetext{
${ }^{5}$ Para um estudo aprofundado sobre esta figura, merece destaque a recente obra de Maria de Fátima Bonifácio (2013), obra naturalmente convocada entre os estudos críticos de Sérgio Nazar David na edição crítica em análise.
} 
de Garrett deste período tão fecundo da sua produção" (p. 42) . É também neste cruzamento de fronteiras, em que o político e o cultural se mesclam, que encontramos as preocupações garrettianas em torno do Conservatório Real de Lisboa, onde sobressai o interesse pelo ensino das artes para este grande homem de cultura.

Assim se consubstancia mais uma razão do enorme interesse destas cartas garrettianas, pela sua relevância para nos inteirarmos melhor do horizonte político-ideológico, mas também cultural e estético do grande autor romântico. Mesmo que nestas cartas - contraditório com o que afirma em outros escritos -, Garrett se afirme sendo mais político do que literato. Afinal, como bem sabemos, na sua criação o escritor fez confluir as dimensões política e estética na sua mundividência crítica. E o reconhecimento público adveio-lhe pelo empenhamento em funções políticas, como como da admirada qualidade das suas obras literárias, num universo onde as duas dimensões da política e da estética se entrecruzam constantemente.

Como é natural neste domínio, este trabalho de edição crítica exige um aturado trabalho de pesquisa e de informação meticulosa que, complementando o conteúdo contextual traçado na Introdução, aduz um número assinalável de notas explicativas dos mais diversos aspectos. Tudo isto é feito com o magno objectivo de enriquecer informativamente todas as grandes referências histórico-culturais presentes nas cartas. Por outras palavras, há a necessidade fundamental de aduzir informação para a mais cabal compreensão deste diálogo epistolar, como aliás salientado por Sérgio Nazar David:

ao lermos e interpretarmos uma carta - sobretudo de um autor da envergadura de Garrett, mais ainda o conjunto ora editado, dirigido a Rodrigo da Fonseca Magalhães, que também vivia em Lisboa -, precisamos de recompor parte do diálogo, que se terá dado fora do registo escrito ou mesmo com terceiros, e também circunstâncias, histórias de vida, instituições, personagens do tempo, referidos sumariamente porque faziam parte de um conhecimento compartilhado (p. 17-18).

\footnotetext{
${ }^{6}$ Em outra passagem, o informado e seguro editor desta correspondência reitera: "As obras de Garrett desse tempo são testemunhos da sua perplexidade perante as complexas e conflituantes forças do social” (p. 44).
} 


\section{5.}

Concluamos rapidamente. Para quem acompanha os estudos garrettianos e oitocentistas de Sérgio Nazar David não fíca surpreendido com a profundidade e a segurança das informações que enformam esta edição crítica do epistolário do autor de Viagens na Minha Terra. Por tudo isto, graças ao profissionalíssimo trabalho de pesquisa de Sérgio Nazar David, passamos a conhecer bem melhor a personalidade do multifacetado Almeida Garrett e alguns dos seus privilegiados interlocutores. O mesmo é dizer que com edições desta qualidade informativa e crítica dispomos hoje de um mais aprofundado conhecimento de uma época, nas dias interligadas dimensões histórica e política, cultural e literária.

Resta-nos desejar o maior sucesso ao plano da Edição das Obras de Almeida Garrett, para que chegue a bom termo, um dos vultuosos contributos para a história literária de Oitocentos. Neste âmbito, espera-se para prevê, da responsabilidade do mesmo investigador a edição crítica de Filipa de Vilhena / A Sobrinha do Marquês, de Almeida Garrett. Cumpre-nos igualmente formular votos de grandes realizações para a recém-criada Cátedra Almeida Garrett, sediada na Universidade do Estado do Rio de Janeiro (UERJ), com um grande potencial de dinamismo na área da Literatura Portuguesa.

\section{REFERÊNCIAS}

AMORIM, Francisco Gomes de. Garrett: Memorias Biographicas, 3 vols. Lisboa: Imprensa Nacional, 1881-84 [obra disponível em formato digital: http://purl. $\mathrm{pt} / 6841]$.

BONIFÁCIO, Maria de Fátima. Um Homem Singular. Biografia Política de Rodrigo da Fonseca Magalhães (1787 -1858). Lisboa: Dom Quixote, 2013.

DAVID, Sérgio Nazar. Cartas de Amor à Viscondessa da Luz. Rio de Janeiro: 7Letras, 2004 - Famalicão: Edições Quasi, 2007.

O Século de Silvestre da Silva, vol. I - Estudos sobre Garrett, A. P. Lopes de Mendonça, Camilo Castelo Branco e Júlio Dinis. Lisboa: Editora Prefácio, 2007)

—. O Século de Silvestre da Silva, vol. II - Estudos Queirosianos. Rio de Janeiro: FAPERJ / 7Letras, 2007). 
- (co-org.). Literatura, História e Política em Portugal (1820-1856). Rio de Janeiro, EdUERJ, 2007 (com trabalho de fixação do texto).

GARRETT, Almeida. Correspondência Familiar. Lisboa, IN-CM, 2012,

Correspondência para Rodrigo da Fonseca Magalhães. Lisboa: Imprensa Nacional-Casa da Moeda (IN-CM), 2016.

. Viagens na Minha Terra. Rio de Janeiro: Nova Fronteira, 2013 (pref. de Sérgio Nazar David).

GRASSI, Marie-Claire. Lire l'Épistolaire. Paris: Armand Colin, 1998.

HAROCHE-BOUZINAC, Geneviève. L'Épistolaire. Paris: Hachette, 1995.

MARTINS, Guilherme d'Oliveira. [Recensão crítica da Correspondência para Luís de Magalhães, de Almeida Garrett], Colóquio-Letras, 197 (2018), pp. 228-230.

MONTEIRO, Ofélia Paiva. Estudos Garrettianos. Rio de Janeiro: EdUERJ, 2010 (pref. de Sérgio Nazar David).

Recebido em: 22/09/2018

Aceito em: 28/01/2019 